\title{
Vaginal mucus resistivity and intenseness of vulva discharge: Dis-Uniformity in trends had zero effect on conception following multiple insemination in Ovsynch- treated Bunaji Cows
}

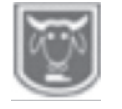

Abstract

Leigh, O. O., Agbugba' L. C., * Ibiam, A. E. and Oyewunmi, A. O. Department of Theriogenology, Faculty of Veterinary Medicine, University of Ibadan

Vaginal mucus resistivity (VMR) and intenseness of vulva discharge (IVD) in 28 Bunaji cows subjected to multiple inseminations at $8^{\text {th }}$ and $16^{\text {th }}$ hours following ovulation synchronization were investigated. Cows were fed silage and crushed elephant grass with clean water provided ad libitum. The VMR and IVD were evaluated using Draminski ${ }^{\circledR}$ bovine estrous probe and visual observation, respectively. The difference between the total mean VMR

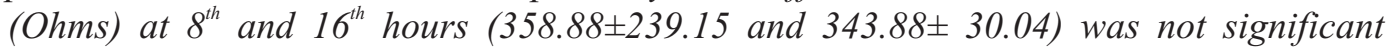
$(P>0.05)$. During $8^{\text {th }}$ to $16^{\text {th }}$-hour, $60 \%$ and $40 \%$ of cows showed rising and declining VMR values, respectively. At the $8^{\text {th }}$ and $16^{\text {th }}$ hours, $60 \%$ and $40 \%$ of the cows had mean VMR that was lower and higher than the total hour-mean values, respectively. At these same hours, $28.57 \%$ and $28.57 \%, 71.43 \%$ and $42.86 \%$ as well as $0 \%$ and $28.57 \%$ of cows had copious, moderate and scant vulva discharges, respectively. All cows were positive for 30-day nonreturn to estrus, caruncular enlargements as well as fetal parts were also palpable at 90-day pregnancy check. We conclude that though, dis-uniformity occurred in vaginal mucus resistivity as well as intenseness of vulva discharge trends between inseminations at the $8^{\text {th }}$ and $16^{\text {th }}$ hours following Ovsynch treatment, this had zero effect on conception and pregnancy establishment in the cows.

Keywords: Vaginal mucus resistivity, vulva discharge, dis-uniformity, insemination, Ovsynch, Bunaji cows.

\section{Introduction}

There is increasing awareness on the importance of artificial insemination in improving the genetic potential of dairy cows in Nigeria. Several changes like alteration in vaginal mucus resistivity and intenseness of the mucus occur during natural estrous cycles in the cow as a result of hormonal interplay during the cycle (Benbia et al., 2011). Hormonal treatment for synchronization has also been reported to influence the biochemical and physical properties of the mucus (Tsiligianni et al., $2001 \mathrm{a}, \mathrm{b})$. The status of vaginal mucus had been reported to influence fertility following insemination in cows (Dunson et al., 1999). Vaginal mucus resistivity had hence been used to predict estrus and the optimum time for insemination with the aim of achieving high pregnancy rates (Rorie et al., 2002; Yamauchi et al., 2009). The intenseness of vaginal mucus which is evident in vulva discharge at periods of artificial insemination has also been associated with fertility in cows (Bernadi et al., 2015). Bunaji cow occupies a high proportion of the Nigerian national herd of cattle and has been kept both for milk and beef(Meghen et al., 1999; Alphonsus et al., 2012). In the study, the trends of vaginal mucus resistivity (VMR) and intenseness of vulva discharge (IVD) and their effect on conception following multiple insemination at the $8^{\text {th }}$ and $16^{\text {th }}$ hours in Ovsynch-treated Bunaji cows were investigated. 


\section{Vaginal-mucus trend dis-uniformity had zero-effect on conception.}

\section{Materials and methods \\ Study site}

The study was carried out at a private dairy Farm in Saki, Oyo State, Southwest Nigeria.

\section{Animals and management}

Twenty eight Bunaji cows ( $>2$ parities, $>60$ days post calving) were used for the study. The age of the animals varied from 2 to 3 years, body weight 250 - $350 \mathrm{Kg}$, and body condition score 3 - 4 on a scale of 5 . The animals were housed in individual pens at night and grazed at day time in fenced paddocks for 3-5 hours daily. The cows were also fed silage and crushed elephant grass. Open cows were selected following rectal palpation as described by Leigh (2018). Briefly, following restraint in a chute, any cow in which amniotic vesicle, membrane slip, caruncles or any fetal part was not palpable, after about 35 days following exposure to a bull, was regarded as open.

\section{Study design}

Cows were inseminated at $8^{\text {th }}$ and $16^{\text {th }}$ hours following Ovsynch treatment. Vaginal mucus resistivity and intenseness of vulva discharge were evaluated prior to each insemination. A 30-day non-return to estrus was evaluated and pregnancy was confirmed at 90-day post insemination via rectal palpation (Leigh, 2018).

\section{Oestrus synchronization}

Oestrus synchronization was carried out using Ovsynch protocol (Pursley et al., 1998). Cows were administered (i/m) $100 \mu \mathrm{g}$ Lecirelin ${ }^{\circledR}$ (Bioveta, Czech Republic) on $\mathrm{d} 0$ followed by administration (i/m) of $25 \mathrm{mg}$ Dinoprost Tromethamine (Zoetis Inc., Spain) on d7 and thereafter a repeat administration of $100 \mu \mathrm{g}$ Lecirelin ${ }^{\circledR}$ on $\mathrm{d} 9$.

\section{Artificial insemination}

Cows were served at $8^{\text {th }}$ and $16^{\text {th }}$ hours post synchronization with Holstein-Friesian semen (ELVIS PL 005317975027 Poland) using standard insemination protocol (Tsuma and Leigh, 2018).

Evaluation of vaginal mucus resistivity (VMR)

Bovine Estrous detector probe (Draminski ${ }^{\circledR}$ Owocowa, Poland) was used to obtain the vaginal mucus resistivity prior to insemination at $8^{\text {th }}$ and $16^{\text {th }}$ hours. Estrous probe and vulva of each cow were cleaned with slightly moist cotton wool. The vulva was slightly lubricated with K-Y jelly and the probe was gently inserted into the anterior vagina. The start button was activated and the probe was rotated, each time pressing the start button until the reading was displayed on the monitor. The resistivity of the vagina mucus was taken as the average of three separate readings per cow prior to insemination at $8^{\text {th }}$ and $16^{\text {th }}$ hours, respectively.

Evaluation of intenseness of vulva discharge (IVD)

The intenseness of vulva discharge was categorized into copious, moderate and scant as described by Bernadi et al. (2015). This was adjudged by visual observation of the quantity of mucus discharge prior to insemination at $8^{\text {th }}$ and $16^{\text {th }}$ hours.

\section{Statistical analysis}

Data was analyzed using descriptive statistics. Mean and standard deviation of vaginal mucus resistivity and proportions of intenseness of vulva discharge at $8^{\text {th }}$ and $16^{\text {th }}$ hours were compared with Paired t-test using the Statistical Package for Social Science (SPSS 23).

\section{Results}




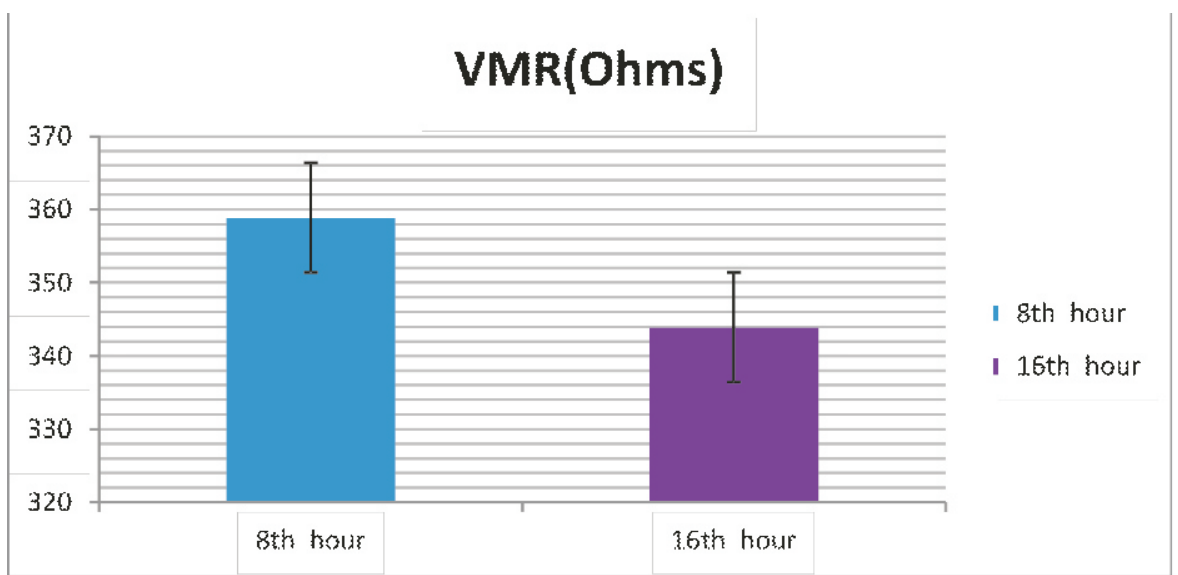

Figure 1 shows the comparison of the mean values of vaginal mucus resistivity (VMR) post-Ovsynch treatment. The difference between the mean values of VMR at the $8^{\text {th }}(358.88+239.15 \mathrm{Ohms})$ and the $16^{\text {th }}$ $(343.88+30.04$ Ohms) hours was not significant $P>0.05$.

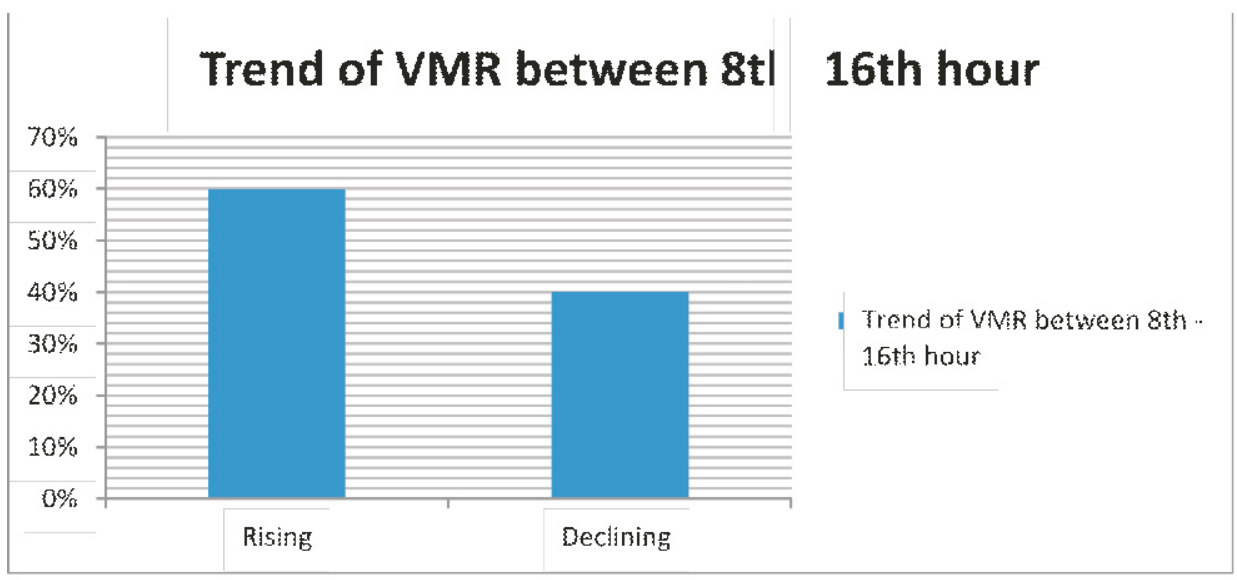

Figure 2 shows the trend of VMR of cows between the $\$$ and $16^{\text {th }}$-hour post-Ovsynch treatment. It showed that $60 \%$ and $40 \%$ of the cows showed rising and declining patterns between the $8^{\text {th }}$ and the $16^{\text {th }}$ hours.

Table 1 shows how VMR of individual cows compared with the average-hourVMR at the $8^{\text {th }}$ and the $16^{\text {th }}$ hours postOvsynch treatment. It showed as follows:
$40 \%$ and $60 \%$ of the cows had higher and lower VMR values compared with the average-hour-values at the $8^{\text {th }}$ (i.e. 358.88 Ohms) and the $16^{\text {th }}$ (i.e. 343.88 Ohms) hours, respectively.

Table 1: Comparison of vaginal mucus resistivity (VMR) of individual cows with the AverageHour-VMR at $8^{\text {th }}$ and $16^{\text {th }}$ hours post Ovsynch Treatment

\begin{tabular}{lll}
\hline & \multicolumn{2}{c}{ Percentage AH-VMR } \\
\cline { 2 - 3 } Average-Hour VMR (Ohms) & Higher & Lower \\
$358.88\left(8^{\text {th }}\right.$ hour) & 40 & 60 \\
$343.88\left(16^{\text {th }}\right.$ hour$)$ & 40 & 60 \\
\hline AH-VMR- Average-Hour VMR & \multicolumn{2}{l}{}
\end{tabular}




\section{Vaginal-mucus trend dis-uniformity had zero-effect on conception.}

Table 2 shows the observations in the intenseness of vulva discharge during the $8^{\text {th }}$ and the $16^{\text {th }}$-hour post-Ovsynch treatment. It showed as follows: copious- $28.57 \%$ to
$28.57 \%(\mathrm{P}>0.05)$, moderate- $71.43 \%$ to $42.86 \%(\mathrm{P}<0.05)$ as well as scant- $0 \%$ to $28.57 \%(\mathrm{P}<0.05)$, during the $8^{\text {th }}$ and the $16^{\text {th }}$ -hour post-Ovsynch treatment, respectively.

Table 2: Comparison of Intenseness of vulva discharge (IVD) of cows during the $8^{\text {th }}$ and the $16^{\text {th }}$ hour post Ovsynch Treatment

\begin{tabular}{llcl}
\hline IVD & \multicolumn{2}{c}{ Period post-Synchronization } \\
& $\mathbf{8}^{\text {th }} \mathbf{h}$ & $\mathbf{1 6}^{\text {th }} \mathbf{h}$ & Significance \\
\hline Copious & $28.57 \%$ & $28.57 \%$ & $\mathrm{P}<0.05$ \\
Moderate & $71.43 \%$ & $42.86 \%$ & $\mathrm{P}<0.05$ \\
Scant & $0 \%$ & $28.57 \%$ & $\mathrm{P}>0.05$ \\
\hline
\end{tabular}

Table 3 shows the observation on conception/pregnancy status of the cows inseminated at $8^{\text {th }}$ and $16^{\text {th }}$ hours post-
Ovsynch treatment. It showed that $100 \%$ of the cows had conceived/were pregnant at 30-day and 90-day following inseminations at $8^{\text {th }}$ and $16^{\text {th }}$ hours post Ovsynch treatment.

Table 3: Conception/Pregnancy status of cows following $8^{\text {th }}$ and $16^{\text {th }}$-hour inseminations post Ovsynch Treatment

\begin{tabular}{lll}
\hline Pregnancy check & \% Pregnant & \% Open \\
\hline 30-day $(\mathrm{n}=28)$ & 100 & nil \\
90-day $(\mathrm{n}=28)$ & 100 & nil \\
\hline
\end{tabular}

\section{Discussion}

Although, the present results suggested similarity between the mean values of vaginal mucus resistivity (VMR) at both the $8^{\text {th }}$ and the $16^{\text {th }}$ hours post Ovsynch treatment in Bunaji cows, the comparative reduction $(\mathrm{P}>0.05)$ shown between the separate mean VMR values between these periods seemed to be expounded by observations on the trend of individual VMR. That most of the cows showed rising VMR while fewer showed declining values between the periods of study suggested some level of dis-uniformity in mucus resistivity trend as the cows progressed from the $8^{\text {th }}$ to $16^{\text {th }}$-hour post synchronization. This position suggests that more cows showed lower VMR values at the $8^{\text {th }}$-hour compared with the $16^{\text {th }}$-hour. Though, further observation on individual VMR and the average-hour-VMR at each stage may suggest contrariwise since equal proportions of cows at both hours had higher and lower VMR compared with the average value, the finding that the proportion of cows in either category was not same suffices to buttress the disuniformity earlier indicated. It is not clear why these fluctuations occurred. Though, it is established that constant changes do occur in the physico-chemical properties of the vaginal mucus during the cycle, the observations indicating dis-uniformity may also have been caused by asynchronous response in the cows to OvSynch treatment (Rivera et al., 2004; Bisinotto et al., 2014). The mean VMR values at $8^{\text {th }}$ and $16^{\text {th }}$ hours were higher $(\mathrm{P}>0.05)$ compared with lower values such as 150-220 Ohms, earlier reported to support good pregnancy outcome in cattle (Ahmed et al., 2017; Subrota et al., 2017). 


\section{Leigh, Agbugba" Ibiam. and Oyewunmi}

This may have been due to changes caused by the synchronizing agents since it is established that their usage always lead to heightened values of vaginal mucus resistivity (BRR, 1999). The observation with intenseness of vulva discharge (IVD) appears to be similar to that of VMR. At the $16^{\text {th }}$ hour, there was no change in proportion of cows with copious discharge whereas there was reduction $(\mathrm{P}<0.05)$ and an increase $(\mathrm{P}<0.05)$ in those with moderate and scant discharges, respectively. The pictures at both $8^{\text {th }}$ and $16^{\text {th }}$ hours for IVD therefore suggest some level of disuniformity similar to what was observed with VMR. Since it had been reported that more copious discharges are characteristic of estrus (Tsiligianni et al., 2001), the trend in the present study as informed by the status at the $8^{\text {th }}$ and the $16^{\text {th }}$ hours can suggest how further the cows were progressed away from estrus. Earlier reports (Murugavel and López-Gatius, 2009; Bernadi et al., 2015) have also associated moderate to copious vulva discharge with good fertility outcomes. The considerable quantities (moderate to copious) of vulva discharge observed at both the $8^{\text {th }}$ and $16^{\text {th }}$ hours post synchronization in the cows is therefore expected to support fertility at both hours. In spite of the dis-uniformities, the conception/pregnancy rate observed in this study was higher than in postpartum dairy cows $(72 \%)$ similarly treated with Ovsynch (Akbarabadi et al., 2014). This may have been so due to the fact that in the present study, multiple insemination was carried out. Unequivocally, our findings among the cows suggest that the dis-uniformity observed in VMR and IVD had zero effect on conception and pregnancy establishment up to 90-day post insemination. While our present findings lend credence to earlier reports that VMR and IVD could be used to predict periods of fertility in cows, the observed disuniformity in trends of VMR and IVD at the $8^{\text {th }}$ and the $16^{\text {th }}$-hour insemination, which though had zero effect on conception and pregnancy establishment, are worth noting.

\section{Conclusion}

The study showed that the status of vaginal mucus resistivity and intenseness of vulva discharge at $8^{\text {th }}$ and $16^{\text {th }}$ hours are not uniform and this dis-unformity had zero effect on conception and pregnancy.

\section{References}

Ahmed, M., Chowdhury, M. K., $\mathbf{R}$ a h m a n, M . M ., Bhat tacharjee, J. and Bhuiyan, M. M. U. 2017. Relationship of Electrical Resistance of Vaginal Mucus during Oestrus with Post-AI Pregnancy in Cows. Bangl. $J$. Vet. Med. Vol 15 (2): 113-117.

Akbarabadi, M. A., Shabankareh, H. K., Abdolmohammadi, A. and Shahsavari, M. H. 2014. Effect of $\mathrm{PGF}_{2 \alpha}$ and $\mathrm{GnRH}$ on the reproductive performance of postpartum dairy cows subjected to synchronization of ovulation and timed artificial insemination during the warm or cold periods of the year. Theriogenology, 82:509516.

Alphonsus, C., Akpa G. N., Barje, P. P., Finangwai, H. I. and Adamu, B. D. 2012. Comparative evaluation of linear udder and body conformation traits of bunaji and friesian $\mathrm{x}$ bunaji cows. World Journal of Life Science and Medical Research, 2(4):134 - 140.

Beef Research Report 1999. The Use of a Vaginal Conductivity Probe to 


\section{Vaginal-mucus trend dis-uniformity had zero-effect on conception.}

Influence Calf Sex Ratio via Altered Insemination Time. A.S. Leaflet R1652.

Benbia, S., Kalla, A., Yahia, M., Belhadi, K. and Zidani, A. 2011. Enzymes activity in bovine cervical mucus related to the time of ovulation and insemination. International Journal of Biological Biomolecular Agricultural Food and Biotechnological Engineering. 5:664-666.

Bernadi, S., Rinaudo, A. and Marini, P. 2015. Cervical mucus characteristics and hormonal status at insemination of Holstein cows. Iranian Journal of Veterinary Research (IJVR), Vol. 17, Pages 45-49.

Bisinotto, R. S., Ribeiro, E. S. and Santos, J. E. P. 2014. Synchronization of ovulation for management of reproduction in dairy cows. Animal, 8 (1), 151-159.

Dunson, D. B., Baird, D. D., Wilcox, A. J. and Weinberg, C. R. 1999. Day-specific probabilities of clinical pregnancy based on two studies with imperfect measures of ovulation. Hum. Reprod. 14(7): 1835-1839.

Leigh, O. O. 2018. Handbook of Bovine Rectal Palpation with notes on the Mare for veterinary students. Stirling-Horden Publishers, $1^{\text {st }}$ ed, Pp. $45-57$.

Meghen, C., MacHugh, D. E., Sauveroche, B., Kana, G. and B radley， D. G. 1999. Characterization of the Kuri Cattle of Lake Chad using Molecular Genetic Techniques. In The origin and development of African livestock. R. M.
Blench and K.C. MacDonald. (eds.) London: University College Press, Pp. 28 - 86.

Murugavel, K. and López-Gatius, F. 2009. Newtonian behavior of the vaginal fluid as a risk indicator of reduced fertility in cows. Indian Vet. J., 86: 12881289.

Pursley, J. R., Silcox, R. W. and Wiltbank, M. C. 1998. Effect of time of artificial insemination on pregnancy rates, calving rates, pregnancy loss, and g e $\mathrm{nder} r$ a t i o a $\mathrm{te} \mathrm{r}$ synchronization of ovulation in lactating dairy cows. J. Dairy Sci. 81:2139-2144.

Rivera, H., Lopez, H. and Fricke, P. M. 2004. Fertility of Holstein dairy heifers after synchronization of ovulation and timed AI or AI after removed tail chalk. Journal of Dairy Science, 87: 2051-2061.

Rorie, R. W., Bilby, T. R. and Lester, T. D. 2002. Application of electronic estrus detection technologies to reproductive management of cattle. Theriogenology 57:137148.

Subrota, M., Nasrin, S. J., Sattwikesh, P., Mohammad M. H., Jayonta B., Habibur, R. M. and Mohammad R. I. 2017. Monitoring vaginal electrical impedance in crossbred cows during post-partum period. Asian J. Med. Biol. Res. 2017, 3 (2), 221-225.

Tsiligianni, Th., Karagiannidis, A., Brikas, P. and Saratsis, Ph. 2001a. Physical properties of bovine cervical mucus during normal and induced by progesterone and/or PGF2alpha 
estrus. Theriogenology. 2001a;55:629-640.

Tsiligianni, Th.., Karagiannidis, A., Brikas, P. and Saratsis, Ph. 2001b. Chemical properties of bovine cervical mucus during normal estrus and estrus induced by progesterone and/or PGF2alpha. Theriogenology. 56:41-50.

Tsuma, V. T. and Leigh, O. O. 2018. Rectal Palpation for artificial insemination in the cow/heifer. In: Handbook of Bovine Rectal Palpation with Notes on the Mare (O.O. Leigh Eds). Stirling-Horden Publishers Ltd. Ibadan. Pp. 45-57.
Yamauchi, S., Nakamura, S., Yoshimoto, T., Nakada, T., Ashizawa, $K$. and Tatemoto, H. 2009. Prediction of estrous cycle and optimal insemination time by monitoring vaginal electrical resistance (VER) in order to improve the reproductive efficiency of the Okinawan native Agu pig. Animal Reproduction Science 113, 311-316.

Received: $19^{\text {th }}$ September, 2018 Accepted: $14^{\text {th }}$ February, 2019 